\title{
Antipodal Vivaldi Antenna to Detect UHF Signals That Leaked Out of the Joint of a Transformer
}

\author{
Jian Zhang, Xiaoxing Zhang, and Song Xiao \\ School of Electrical Engineering, Wuhan University, Wuhan, China \\ Correspondence should be addressed to Song Xiao; xiaosongxs@gmail.com
}

Received 13 December 2016; Revised 4 April 2017; Accepted 9 May 2017; Published 1 June 2017

Academic Editor: Symeon Nikolaou

Copyright (C) 2017 Jian Zhang et al. This is an open access article distributed under the Creative Commons Attribution License, which permits unrestricted use, distribution, and reproduction in any medium, provided the original work is properly cited.

\begin{abstract}
In recent years, extensive research has been conducted on the ultrahigh-frequency (UHF) method. Considering that acquiring a partial discharge UHF signal is the first step in a series of tasks, such as fault diagnosis and defect location, the UHF sensor plays an important role in the UHF method. An antipodal Vivaldi antenna installed at a transformer's joint is designed in this study according to the structural features of $750 \mathrm{kV}$ transformers in China. Several effective structures, such as linear gradient microstrip and slot edge, are employed to improve the return loss and radiation characteristics. A metal box is designed after analyzing the influence of the metal around the antenna. The metal box can effectively shield against electromagnetic interference and does not deteriorate the performance of the antenna significantly. Experimental data show that this antenna is much more sensitive than the rectangular plane spiral antenna. The proposed antipodal Vivaldi antenna is suitable for detecting partial discharge in large transformers.
\end{abstract}

\section{Introduction}

Several local defects, such as bubbles, cracks, burr on the electrode, and suspended conductive particles, are difficult to avoid in the manufacture process of transformers [1]. These defects cause uneven distribution of the electric field, which results in the generation of partial discharge and prompts transformer insulation degradation. Statistics show that transformer accidents are mostly caused by insulation degradation [2]. Partial discharge is accompanied by numerous phenomena, such as light, electric pulse, ultrasonic wave, and electromagnetic wave. By detecting these phenomena, partial discharge can be detected indirectly. The dielectric insulation status and defect types can be determined, and the insulation life of the electrical equipment can even be predicted. Therefore, current research institutions, manufacturers, and electric power system operation departments place a high value on partial discharge detection technology.

Rutgers from the Netherland KEMA Laboratory and Judd from the University of Strathclyde found that the rising edge of oil-immersed transformer partial discharge signals is steep, and the pulse width is in nanoseconds (more than $1 \mathrm{GHz}$
UHF signals can be stimulated) [3-5]. Thus, the ultrahighfrequency (UHF) method was established and is currently used widely because of its strong anti-interference ability, high positioning accuracy, and other advantages [6].

The UHF antenna sensor plays an important role in the UHF method. It can be divided into two types, namely, builtin and external, according to the difference in antenna installation position. Typical built-in antennas include monopole [7], Hilbert [8], and Goubau antennas [9]. They are usually installed in the hand hole, manhole, and oil drain valve. Builtin antennas possess high detection sensitivity and strong antiinterference ability, but the transformers put into operation usually cannot be modified. Common external antennas include Archimedes and planar equiangular spiral antennas [10-12]. These antennas can be installed at the dielectric window and the casing. Mounting the sensors at the dielectric window is recommended by the International Council on Large Electric Systems and is the most commonly used method at present [13]. However, the dielectric window needs to be reserved in the transformer factory, so many transformers that have been put into operation cannot be modified. Furthermore, installing the sensors at the casing 


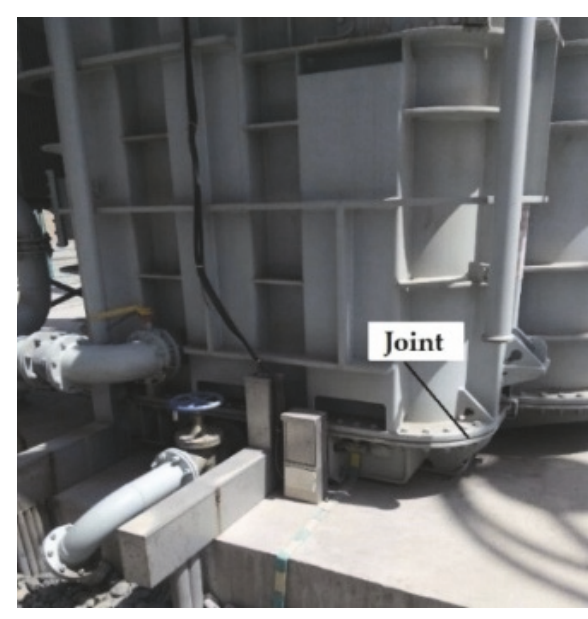

(a)

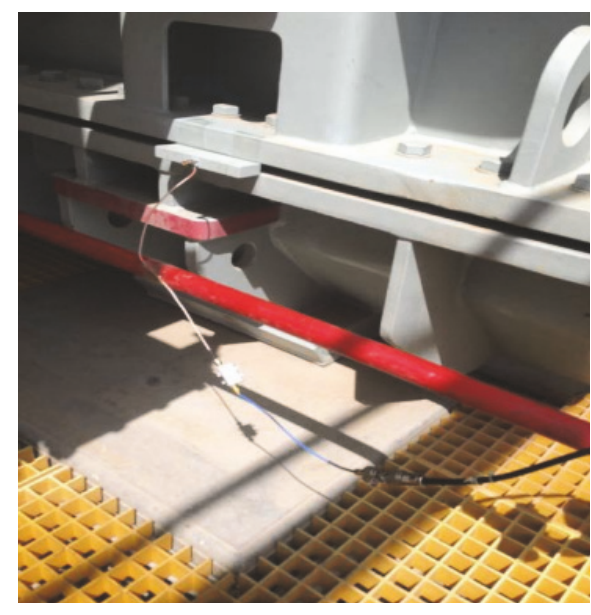

(b)

FIGURE 1: Joint between the barrel and base of a $750 \mathrm{kV}$ transformer.

decreases the creepage distance of the casing. As shown in Figure 1, the $750 \mathrm{kV}$ oil-immersed transformer in China has a certain particularity. The Chinese power transformer maintenance guidelines indicate that a transformer must be overhauled within the first five years and every 10 years after that. In the process of overhaul, the barrel is moved to repair the iron core and winding, and this procedure differs from those adopted in other countries. Therefore, the transformer gasket used in China is much larger, and a joint that is about $2 \mathrm{~cm}$ exists between the barrel and the base. Several Chinese scholars have conducted preliminary studies on utilizing this joint to detect partial discharge. They used Archimedes and planar equiangular spiral antennas to receive the signals in a laboratory [14-19]. Considering that these scholars merely wished to prove that signals can leak out of the joint, many factors, such as electromagnetic interference, influence of metal around the antenna, and installation, were not considered. However, these studies provided a new means of transformer partial discharge online monitoring.

When the antenna is installed on the transformer, it is inevitably placed near the transformer metal shell. Usually, the influence of metal around the antenna is ignored in the UHF antenna sensor design. However, this disregard seriously degrades the performance of external antennas and is one of the important reasons for low sensitivity, which is shortage limitation of previous designs. In this study, we reduced the deterioration in antenna performance as much as possible by designing a metal box. The box also shields against electromagnetic interference. The laboratory experiment showed that the antenna can meet the requirements of partial discharge detection for subsequent UHF signal analysis.

\section{Design of the UHF Antenna Sensor}

2.1. Selection of the UHF External Antenna Sensor. The UHF external antenna sensor should meet the following requirements:

(1) Broadband and appropriate working band: the signal generated by partial discharge is weak over $3 \mathrm{GHz}$.
Thus, extending the antenna bandwidth below $3 \mathrm{GHz}$ can effectively increase the received signal energy and can collect abundant spectrum information.

(2) High gain: the propagation loss in the joint is large; a high-gain antenna will increase antenna sensitivity.

(3) Easy to install: given that the $750 \mathrm{kV}$ transformer joint is wide and deep, inserting the antenna into the joint is indeed the most convenient means of installation. Furthermore, it will decrease the energy loss before signals are received and improve the problem that the signals received by the external antenna have low signal intensity. Based on this consideration, a broadband and high-gain Vivaldi antenna was selected in this study as the detection antenna.

The Vivaldi antenna can be classified into three types: typical, antipodal, and balanced [20-22]. The main difference between them is the feeding mode. The typical Vivaldi antenna uses the microstrip-slotline balun. Given that the characteristic impedance of the slotline increases monotonically with increasing frequency, it exhibits obvious dispersion properties and possesses certain return and insertion losses in a broadband. The antipodal Vivaldi antenna uses the microstrip balun; it has almost unchanged characteristic impedance and shows low dispersion properties, which are the advantages of the antipodal Vivaldi antenna. The balanced Vivaldi antenna uses the stripline balun, whose transmission loss is lower than that of the microstrip one. However, the stripline is buried in the dielectric layer and is difficult to process and weld. Thus, the antipodal Vivaldi antenna was selected as the final design in this study.

\subsection{Basic Structure and Principle of the Antipodal Vivaldi} Antenna. As shown in Figures 2 and 3, the antipodal Vivaldi antenna consists of a substrate and bonding copper on both sides of the substrate. It can be divided into two parts: radiation area and balun. Given that transmitting and receiving antennas are equivalent, the transmitting antenna was utilized to explain the basic principle. After an electromagnetic 


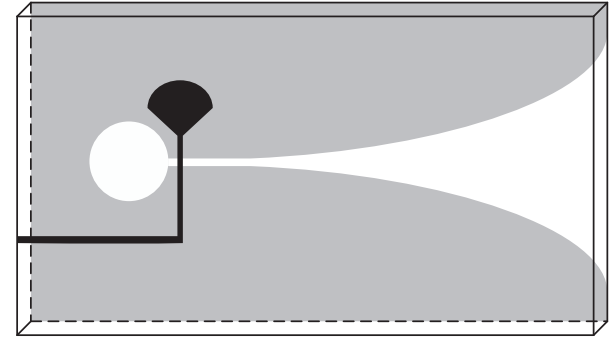

(a)

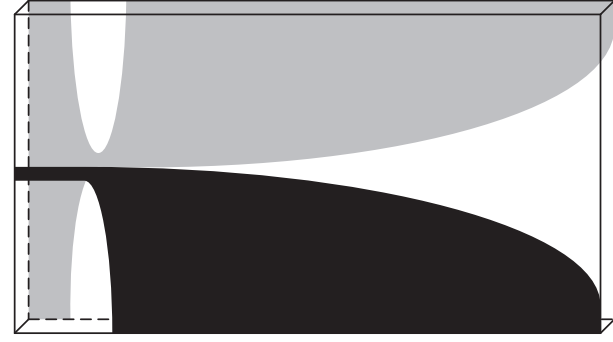

(b)

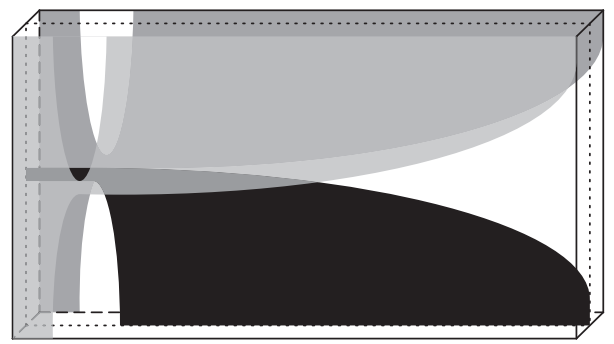

(c)

FIGURE 2: Three types of Vivaldi antennas.

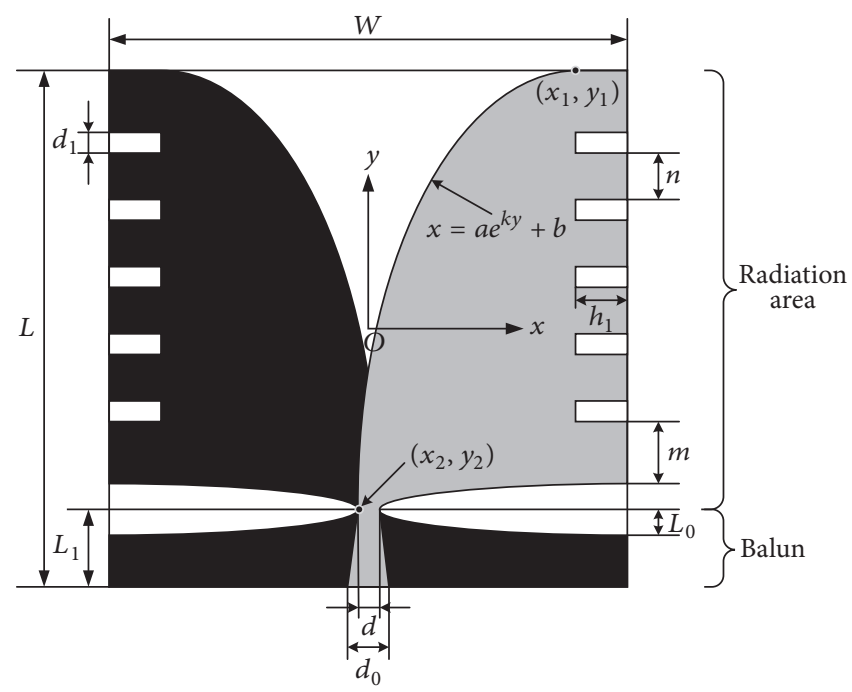

Figure 3: Antipodal Vivaldi antenna.

wave is transmitted from the balun to the radiation area, it radiates from the tapered slot to the free space. A lowfrequency electromagnetic wave radiates from the wide area of the slot because of the long wavelength. Simultaneously, a high-frequency electromagnetic wave radiates from the narrow area of the slot. This is the main reason why the Vivaldi antenna possesses the characteristics of broadband and stable directivity. If the wavelength of the electromagnetic wave is more than twice the maximum slot width of the Vivaldi antenna, it would not radiate efficiently, and the radiation pattern would gradually become similar to that of a monopole.

The final parameters of the antenna are shown in Table 1 , in which $h$ is the substrate thickness. The other parameters are shown in Figure 3.
2.3. Design of an Antipodal Vivaldi Antenna. In the initial phase of antenna design, the substrate material should not affect the subsequent parameter calculation. In antenna design, FR4 (dielectric constant $=4.4$, dielectric loss tangent $=0.02$ ) is often utilized as the substrate because of its low price. However, FR4 has two disadvantages. One is that its high dielectric loss tangent causes a large energy loss. The other is that FR4 from different manufacturers and various batches have different doping concentrations, which make the dielectric constant unstable. Controlling the characteristic impedance of this antenna is difficult, so FR4 is always utilized in the band of less than $1 \mathrm{GHz}$. In this study, Teflon (dielectric constant $=2.2$, dielectric loss tangent $=0.001$ ) was used as the substrate. 
TABLE 1: Design parameters with final optimized dimension of the antipodal Vivaldi antenna.

\begin{tabular}{lc}
\hline Dimension & Value $(\mathrm{mm})$ \\
\hline$W$ & 100 \\
$L$ & 100 \\
$h$ & 2 \\
$h_{1}$ & 10 \\
$d$ & 4.1 \\
$d_{0}$ & 6.3 \\
$d_{1}$ & 4 \\
$L_{0}$ & 5 \\
$L_{1}$ & 15 \\
$k$ & 30 \\
$x_{1}$ & 40 \\
$m$ & 16 \\
$n$ & 7 \\
\hline
\end{tabular}

2.3.1. Selection of the Shape of the Inner Edge. The tapered slot is the main radiation area. Therefore, the shape of the inner edge is the key factor in antenna performance. The exponential profile curves provide the antenna with relatively better performance than the parabola, the trigonometric function, and so on [23]. However, analyzing the antipodal Vivaldi antenna in theory is difficult because of the changeable characteristic impedance and transmission constant of the tapered slot [24]. In this study, the antenna was mainly designed through simulation calculation. For a convenient simulation calculation, a coordinate system was established and is shown in Figure 3. Two endpoints, namely, $\left(x_{1}, y_{1}\right)$ and $\left(x_{2}, y_{2}\right)$, and $k$ were set as variables. The exponential profile curves employed in this design can be described by

$$
\begin{aligned}
& x= \pm\left(a e^{k y}+b\right), \\
& a=\frac{x_{1}-x_{2}}{e^{k y_{1}}-e^{k y_{2}}}, \\
& b=\frac{x_{2} e^{k y_{1}}-x_{1} e^{k y_{2}}}{e^{k y_{1}}-e^{k y_{2}}},
\end{aligned}
$$

where $x_{1}$ and $x_{2}$ are the abscissa of two endpoints, $y_{1}$ and $y_{2}$ are the ordinate of two endpoints, $k$ is the gradual change ratio of the exponential function, and $a$ and $b$ are two parameters of the exponential function. Through simulation calculation, the optimal parameters are $k=30, x_{1}=40 \mathrm{~mm}, x_{2}=$ $-35 \mathrm{~mm}$, and $y_{2}=-2.05 \mathrm{~mm}$.

2.3.2. Design of the Balun. The balun is a balanced-unbalanced transformer. It has two main functions:

(1) Change high-frequency signals from a single input to a balanced output.

(2) Achieve impedance matching at the input and output.

Through simulation calculation, the optimal impedance matching between the microstrip and radiation area was determined to occur in $d=4.1 \mathrm{~mm}$. However, the characteristic impedance is $65 \Omega$ when $h=2 \mathrm{~mm}$ and $d=4.1 \mathrm{~mm}$. This

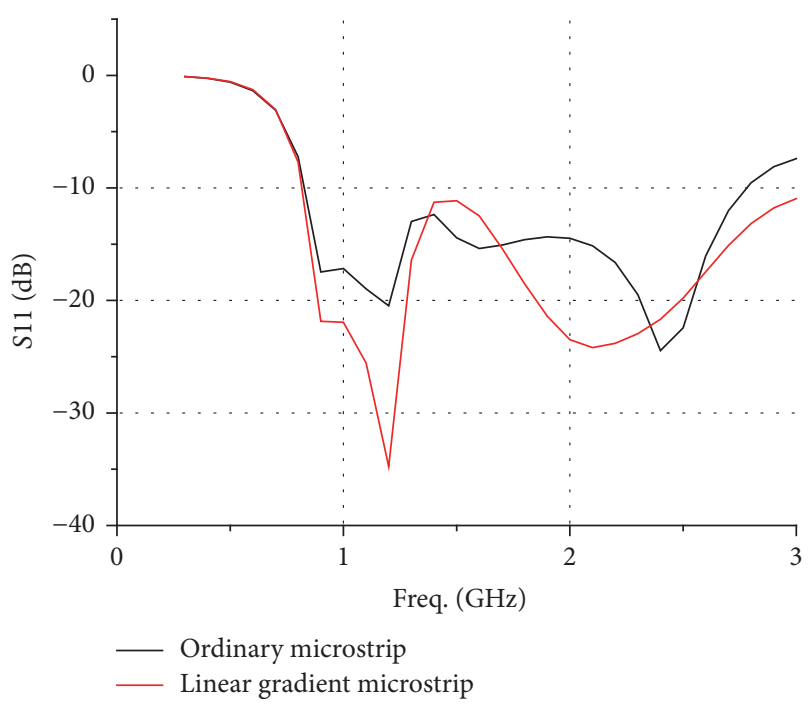

FIGURE 4: Influence of different microstrips on the return loss of the antenna.

condition indicates that a certain energy loss occurs when the microstrip is connected to a $50 \Omega$ coaxial cable directly. Therefore, to ensure impedance matching between the microstrip and $50 \Omega$ coaxial cable, the microstrip was designed as a linear gradient structure in this study, as shown in Figure 3. The calculation formula of microstrip characteristic impedance showed that $d_{0}=6.3 \mathrm{~mm}$.

As shown in Figure 4, the linear gradient microstrip generally decreases the return loss of the antenna (S11). The working band is widened from $0.825-2.78 \mathrm{GHz}$ to $0.815-3 \mathrm{GHz}$.

2.3.3. Optimization of the Radiation Area. Several common optimization methods are available. The first method involves etching slots on the fins. This method can efficiently increase gain and improve return loss [25]. The second method involves circular termination and a double exponentially tapered slot. Their effect is similar to that of the first method $[26,27]$. The third method is parasitic ellipse and dielectric lens. These two can increase the gain at a high frequency [28, 29]. Given that we mainly focused on low-frequency bands, we selected the simplest method, that is, the first method.

This etching procedure causes the current distribution to concentrate on the inner edge and more energy to radiate from the tapered slot, thereby increasing the gain and improving the return loss. Figure 5 shows the surface current distribution at $3 \mathrm{GHz}$. The surface current at the inner edge is large when slots are etched on the fins. Considering that the surface current is large on the balun and the junction between the balun and radiation area, we did not view this part to avoid misleading.

The process of determining the slot number, size, and location was divided into two parts to reduce the time cost of simulation calculation:

(1) The number of symmetrical regular slots was determined. The conditions of 3-7 pairs of equal-height slots were simulated. By adjusting $h_{1}, d_{1}, m$, and $n$, 


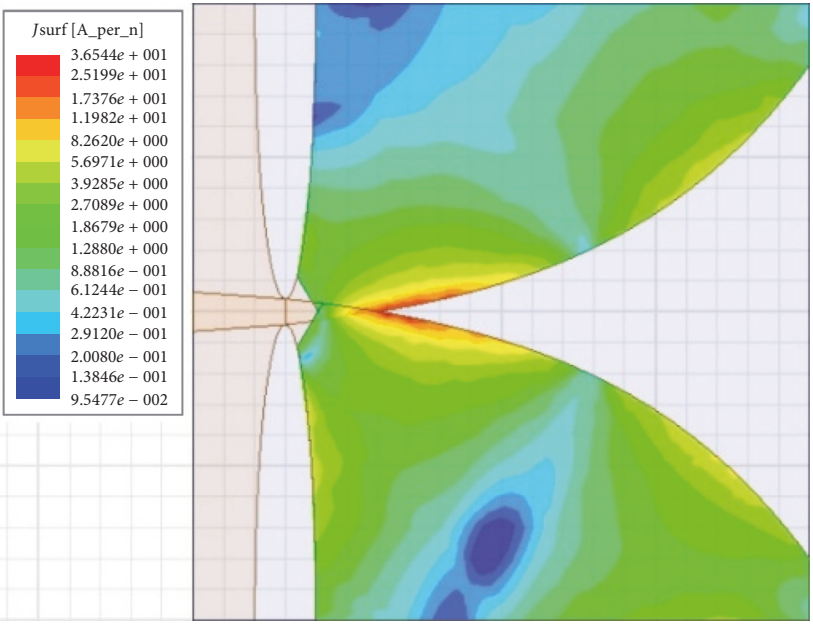

(a) No slots

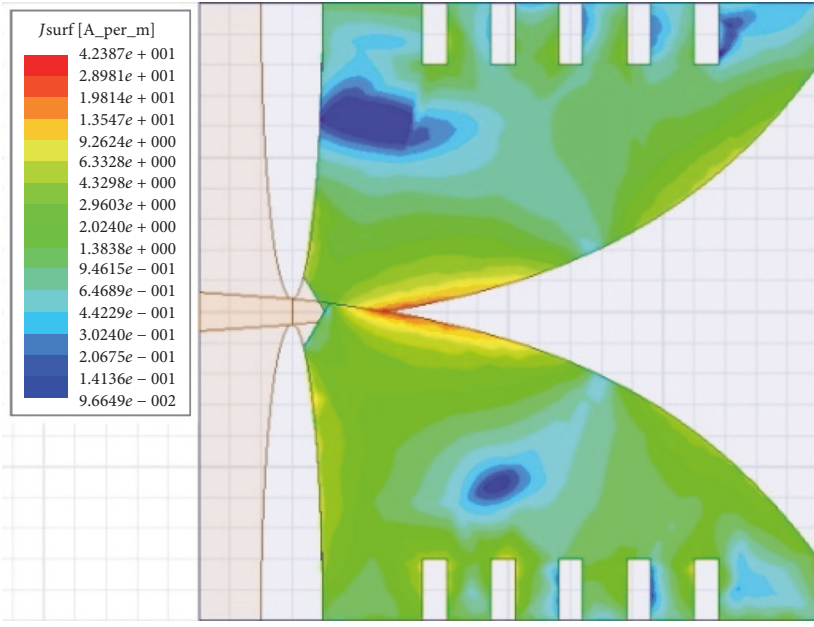

(b) Five pairs of slots

FIGURE 5: Surface current distribution.

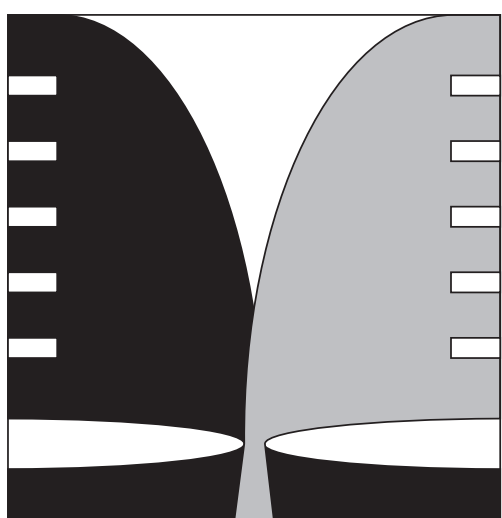

(a)

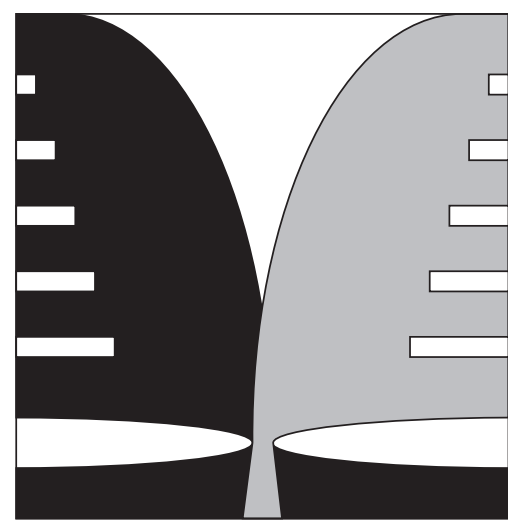

(b)

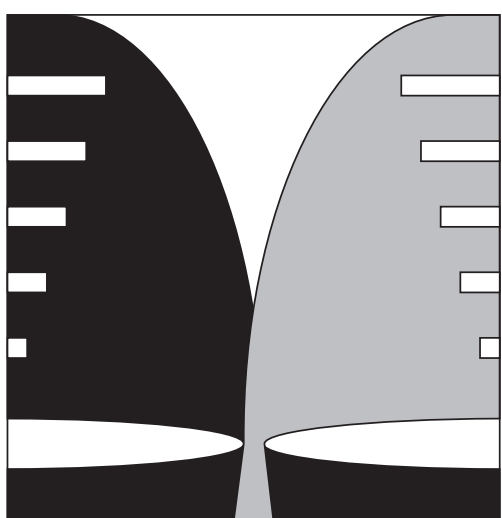

(c)

FIGURE 6: Three different patterns of slots: (a) equal-height slots; (b) the height of the slots decreases linearly along the direction of the antenna opening; (c) the height of the slots increases linearly along the direction of the antenna opening.

every condition's optimal $S_{11}$ curve and gain were obtained.

(2) The pattern of the slots was determined. Under the condition of optimal numbers of slots, three different patterns of slots were simulated. As shown in Figure 6, the patterns were equal-height slots, the height of the slots increases, and the height of the slots decreases linearly along the direction of the antenna opening. The optimal results were obtained and compared.

Figure 7 and Table 2 show that the slot edge improves the performance of $S 11$ and gain. However, the number of slots exerts a minimal effect on S11 and gain. In general, the performance of $S 11$ is slightly better than that of gain when five or six pairs of slots are etched on the fins; the performance of gain is the best when five pairs of slots are etched on the fins.

Figure 8 and Table 3 show that the return loss is slightly poorer at about $1.1 \mathrm{GHz}$ than that in the other two conditions when slots with linearly increased height are etched on the fins. The gain is slightly poorer than that in the other two conditions when slots with linearly decreased height are etched on the fins. Thus, equal-height slots were determined as the final pattern of slots.

2.3.4. Measured S11 and Simulated Radiation Pattern of the Antipodal Vivaldi Antenna. Figure 9 presents a photograph of the fabricated antenna. Figure 10 shows a comparison of simulated and measured data on return loss obtained from the network analyzer. The working band of the antenna is $0.807-3 \mathrm{GHz}$. A certain difference exists between the simulated and measured curves because of the simulation and manufacturing error. The simulation error mainly originates from the grid division and cannot be too fine. The manufacturing error mainly originates from the burrs generated by welding. However, the overall trend is similar. This result indicates that the simulation calculation is reliable.

In Figure 11, the solid lines denote the $H$ plane, and the dashed lines denote the $E$ plane. Figure 12 shows the gain in the $y$ direction versus frequency in $2 \mathrm{D}$. The antenna has strong directivity at 2 and $3 \mathrm{GHz}$. However, it 
TABLE 2: Influence of different numbers of slots on gain in the $y$ direction at different frequencies.

\begin{tabular}{|c|c|c|c|c|c|}
\hline Numbers of slots/pairs & $1 \mathrm{GHz} / \mathrm{dB}$ & $1.5 \mathrm{GHz} / \mathrm{dB}$ & $2 \mathrm{GHz} / \mathrm{dB}$ & $2.5 \mathrm{GHz} / \mathrm{dB}$ & $3 \mathrm{GHz} / \mathrm{dB}$ \\
\hline 0 & -3.5 & 2.7 & 5.6 & 6.7 & 7.7 \\
\hline 3 & -3.5 & 3.6 & 6.3 & 6.7 & 9.4 \\
\hline 4 & -3.6 & 3.7 & 6.3 & 6.7 & 9.2 \\
\hline 5 & -3.6 & 3.7 & 6.4 & 6.9 & 9.4 \\
\hline 6 & -3.6 & 3.9 & 6.3 & 6.7 & 9.2 \\
\hline 7 & -3.5 & 3.9 & 6.4 & 6.8 & 9.4 \\
\hline
\end{tabular}

TABLE 3: Influence of different patterns of slots on gain in the $y$ direction at different frequencies.

\begin{tabular}{|c|c|c|c|c|c|}
\hline Patterns of slots & $1 \mathrm{GHz} / \mathrm{dB}$ & $1.5 \mathrm{GHz} / \mathrm{dB}$ & $2 \mathrm{GHz} / \mathrm{dB}$ & $2.5 \mathrm{GHz} / \mathrm{dB}$ & $3 \mathrm{GHz} / \mathrm{dB}$ \\
\hline Equal height & -3.6 & 3.7 & 6.4 & 6.9 & 9.4 \\
\hline Linearly decreased & -3.5 & 3.6 & 6.3 & 6.4 & 8.9 \\
\hline Linearly increased & -3.6 & 3.9 & 6.3 & 7.1 & 9.1 \\
\hline
\end{tabular}

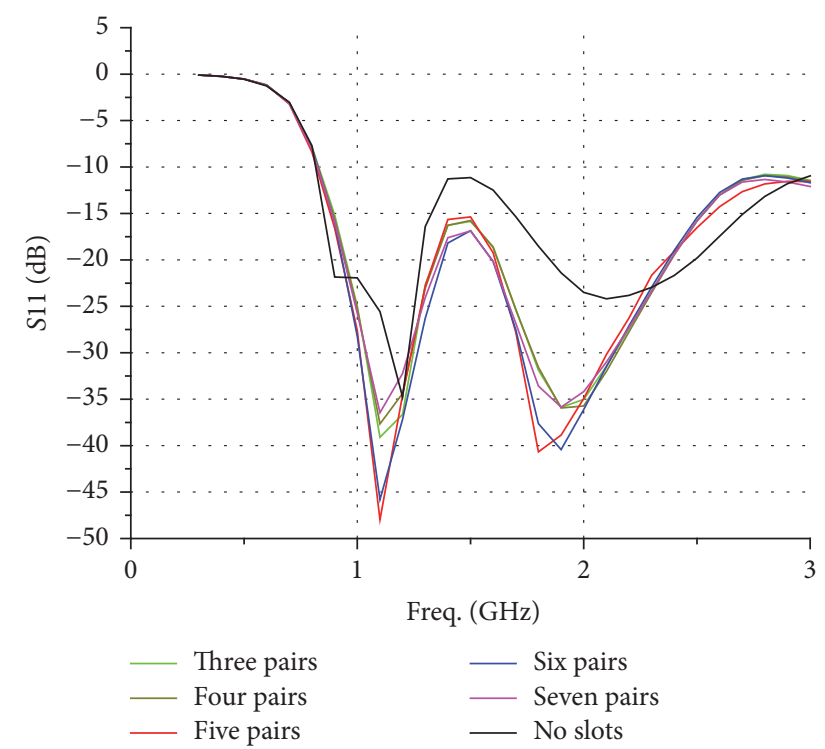

Figure 7: Influence of different numbers of slots on the return loss of the antenna.

becomes an omnidirectional antenna below $1.4 \mathrm{GHz}$ because the wavelength of the electromagnetic wave is more than twice the maximum tapered slot width of the antenna. Two stages were observed. The radiation pattern between 1 and $1.4 \mathrm{GHz}$ is similar to that in Figure $11(\mathrm{~b})$ and to that in Figure 11(a) below $1 \mathrm{GHz}$. Although the gain in the $y$ direction is low, the maximum gain is about $2 \mathrm{~dB}$, which indicates that radiation ability still exists. Therefore, the input resistance is not immediately reduced to 0 below $1.4 \mathrm{GHz}$, as shown in Figure 13. The antenna demonstrates good return loss between 0.8 and $1.4 \mathrm{GHz}$.

To insert the antenna into the joint, the antenna needs to be miniaturized. Therefore, we performed a detailed simulation at a low frequency. We found that the etched slots cannot reduce the working frequency, which is different from the conclusions of other researchers. If the minimum wavelength of the lowest working frequency is $\lambda$, the size of

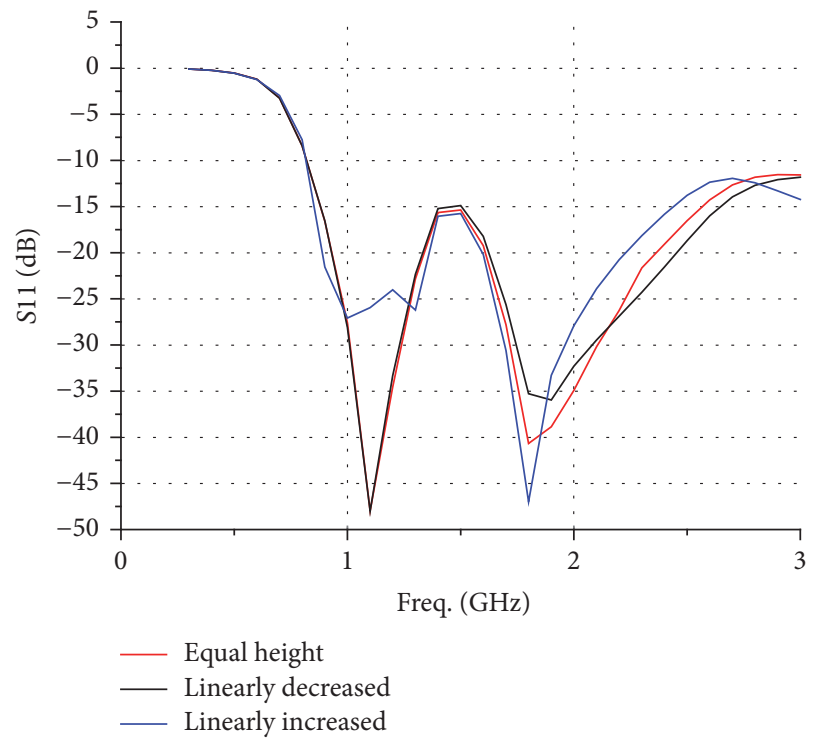

Figure 8: Influence of different patterns of slots on the return loss of the antenna.

this antenna is $0.267 \lambda \times 0.267 \lambda$, which most of the antipodal Vivaldi antennas cannot reach.

\section{Laboratory Experiments on the Antipodal Vivaldi Antenna}

The installation method of the antenna and the experiment platform are shown in Figure 14. A $10 \mathrm{kV}$ three-phase transformer was used as the experiment platform because of the limited laboratory conditions. Its external dimensions are $800 \mathrm{~mm} \times 465 \mathrm{~mm} \times 590 \mathrm{~mm}$. Its cover is lifted by $2 \mathrm{~cm}$ to simulate the joint of a $750 \mathrm{kV}$ transformer. The needle-to-plate model immersed in transformer oil was used to simulate the real source of partial discharge. After the installation was completed, the voltage on the needle-to-plate model was increased by a transformer until partial discharge was generated. Then, the voltage, pulse current signals, and 


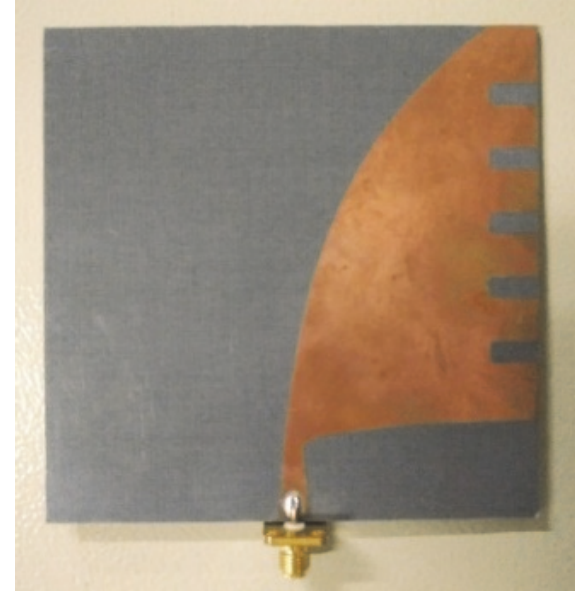

(a)

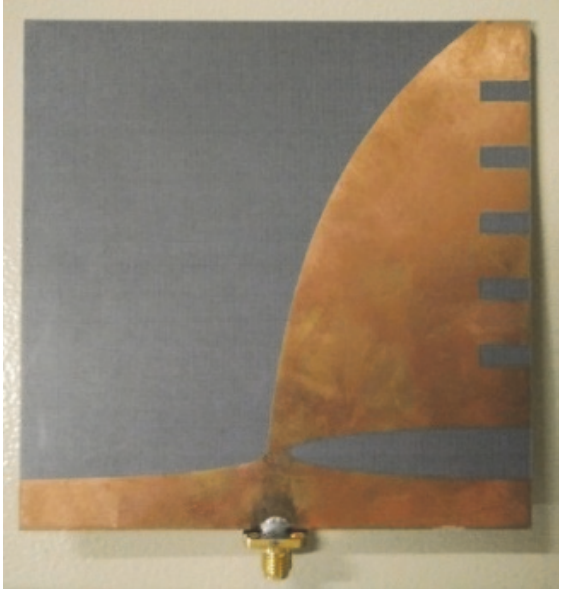

(b)

FIGURE 9: Photograph of the fabricated antenna.

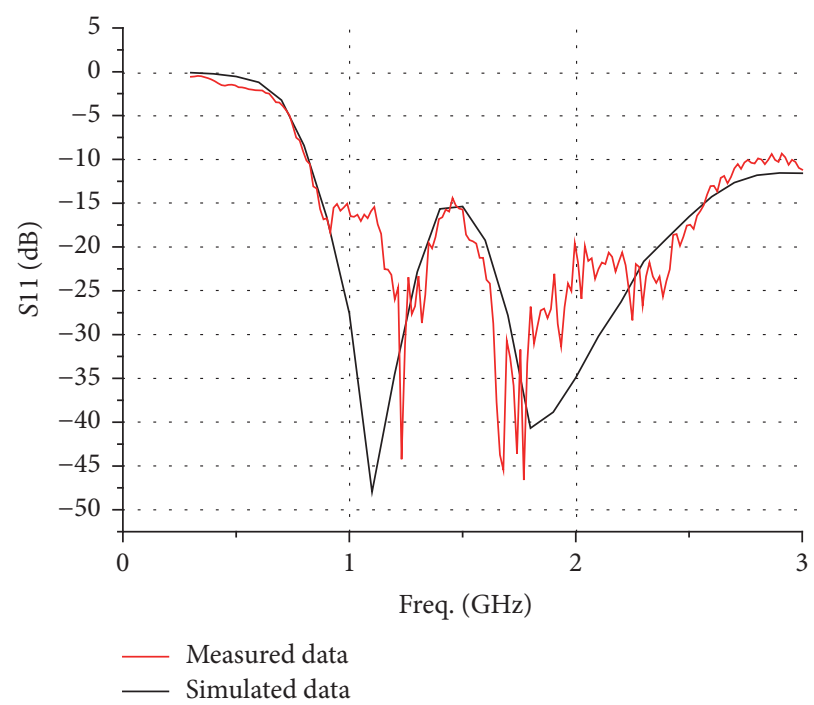

Figure 10: Comparison of simulated and measured data on return loss.

UHF signals were obtained by a voltage divider, measured impedance, and antenna.

3.1. Design of the Metallic Shell of the Antipodal Vivaldi Antenna. A large amount of electromagnetic interference exists, so external antenna sensors should be placed in a metal box to shield them against the electromagnetic interference originating from the flank and back. The metal box is shown in Figure 15(a). Figure 16 shows that the metal around the antenna sharply reduces the return loss. Reference [30] indicated that the absorbing material can improve the return loss. However, the efficiency and gain of the antenna are reduced at the same time. Experimentation revealed that almost no difference is observed in the amplitude of received signals regardless of whether an absorbing material exists in the metal box. The area of the absorbing material covering the surface inside the box exerts a minimal effect on amplitude.
Therefore, changing the structure of the metal box is the only means to improve antenna sensitivity.

The simulation calculation showed that adjusting the size of the metal box slightly, changing the shape of the metal box, and adding an extra metal structure in the metal box cannot improve the return loss. However, in the process of simulation calculation, the return loss will be improved if several extra parts of the metal box are removed. To maintain the directivity of the antenna, a metal box was fabricated, as shown in Figure 15(b). However, it could not shield against the electromagnetic interference. The metal box was improved further, as shown in Figure 15(c). Two layers of metallic shell were added. The inner metal box using the structure is shown in Figure 15(b), and the outer metal box using the structure but with a larger size is shown in Figure 15(a). In the field test, the inner metal box and antenna were inserted into the joint initially and then the joint was covered with the outer metal 


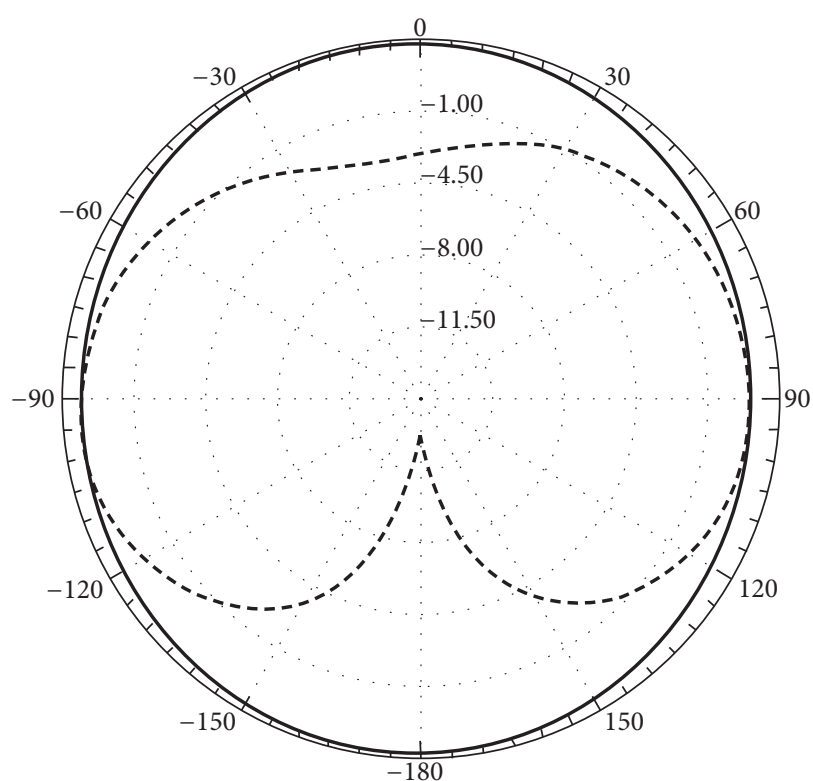

(a) $0.8 \mathrm{GHz}$

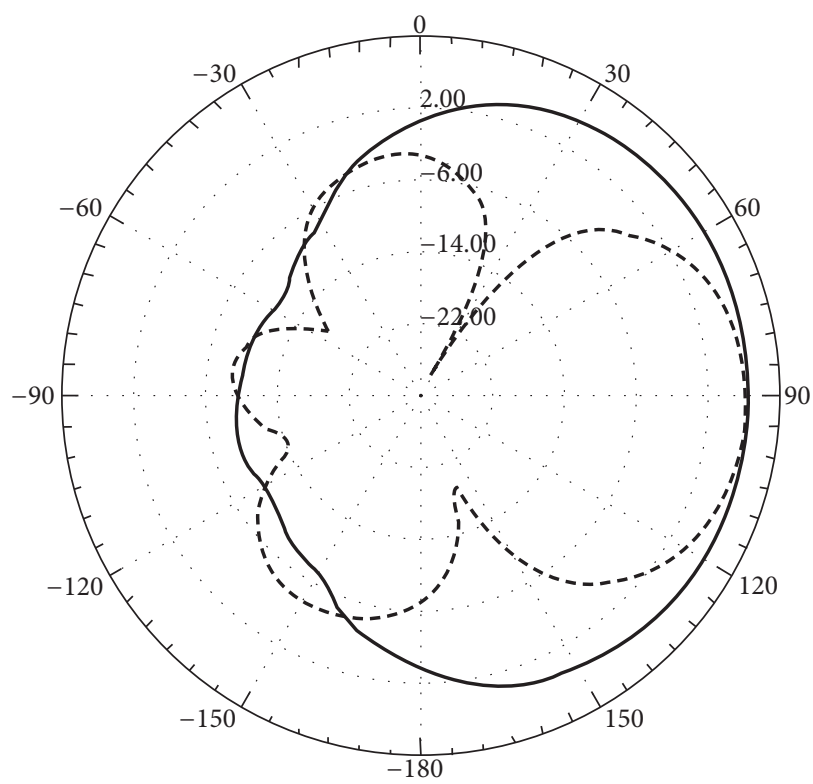

(c) $2 \mathrm{GHz}$

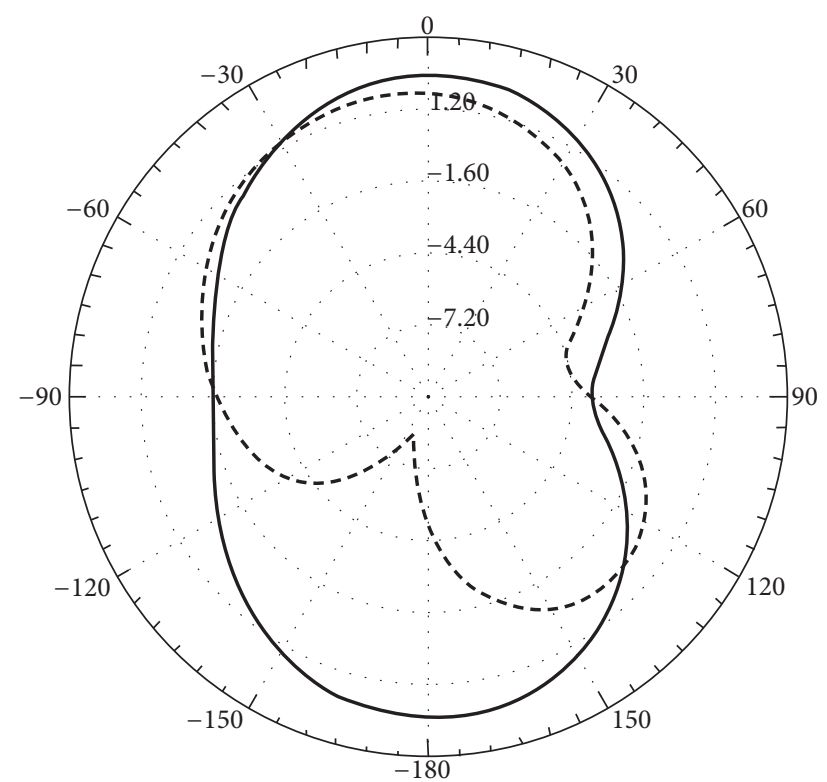

(b) $1 \mathrm{GHz}$

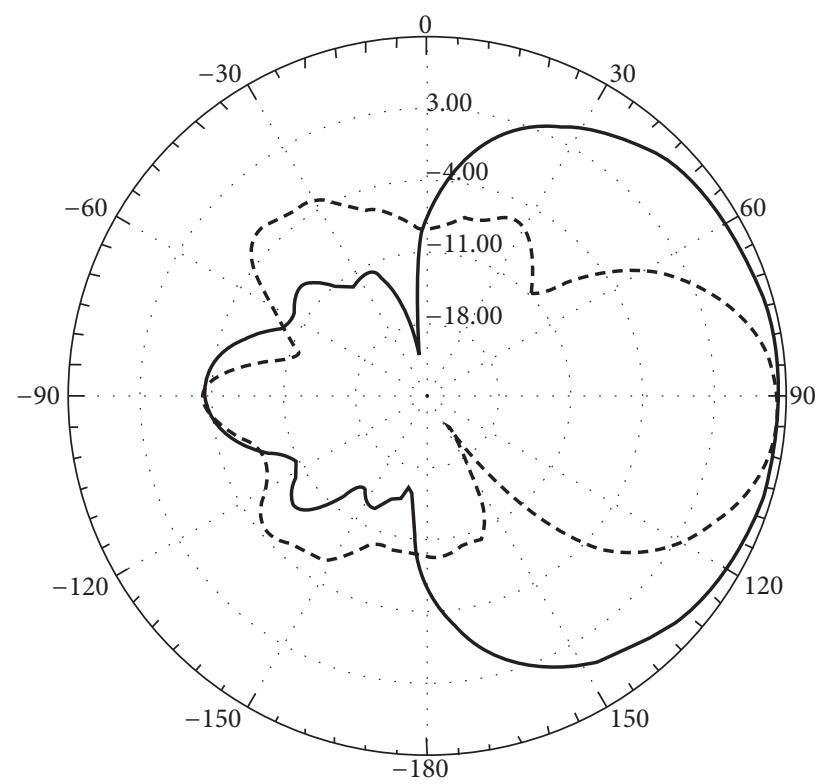

(d) $3 \mathrm{GHz}$

FIGURE 11: Radiation pattern of the antipodal Vivaldi antenna at different frequencies.

box. The outer box can be properly changed as long as there is enough space on either side of the inner metal box. Figure 16 shows that the return loss in the third condition is slightly poorer than that in the second condition but is much better than that in the first one.

3.2. Receiving Performance Test for the Antipodal Vivaldi Antenna. At the inception voltage, the abovementioned antennas with three different metallic shells and a rectangular plane spiral antenna were used to receive the electromagnetic wave that leaked out of the joint [31]. Their positions are shown in Figure 17, and the single received signal's waveform is shown in Figure 18. The antenna shown in Figure 15(b) exhibits the best performance in terms of sensitivity. The amplitude of the signal received by this antenna is seven times that received by the rectangular plane spiral antenna. The antenna shown in Figure 15(c) is slightly poorer but is still more sensitive than the rectangular plane spiral antenna. The measured result agrees with the analysis in Section 3.1.

3.3. Characteristic of Partial Discharge in Transformer Oil. As shown in Figure 19, the partial discharge signals in a powerfrequency cycle were acquired through UHF and pulse current methods. The power-frequency cycle was acquired from the voltage divider. The partial discharge mainly occurs in the one-fourth and three-fourth cycles. The amplitude 


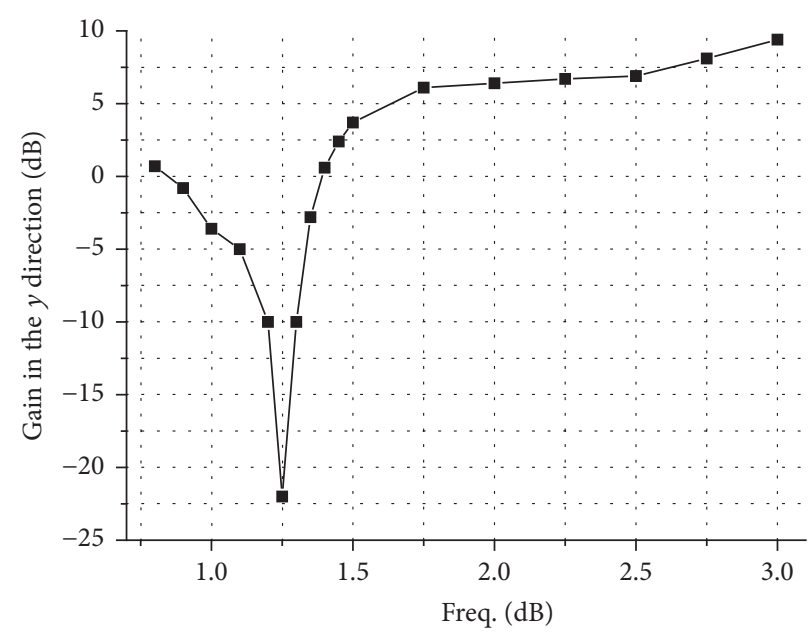

FIGURE 12: Gain in the $y$ direction versus frequency in 2D.

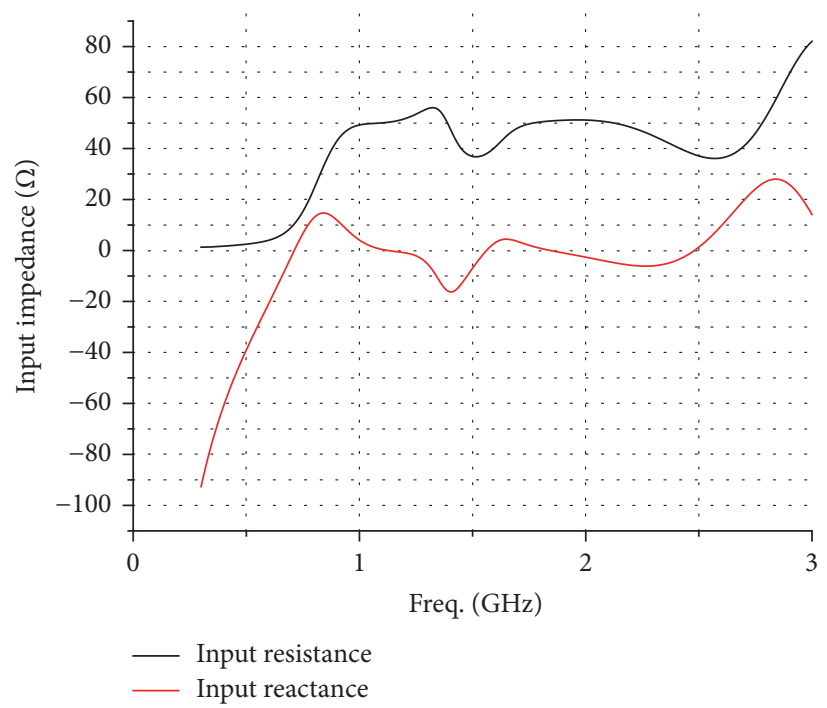

FIGURE 13: Input impedance of the antipodal Vivaldi antenna.

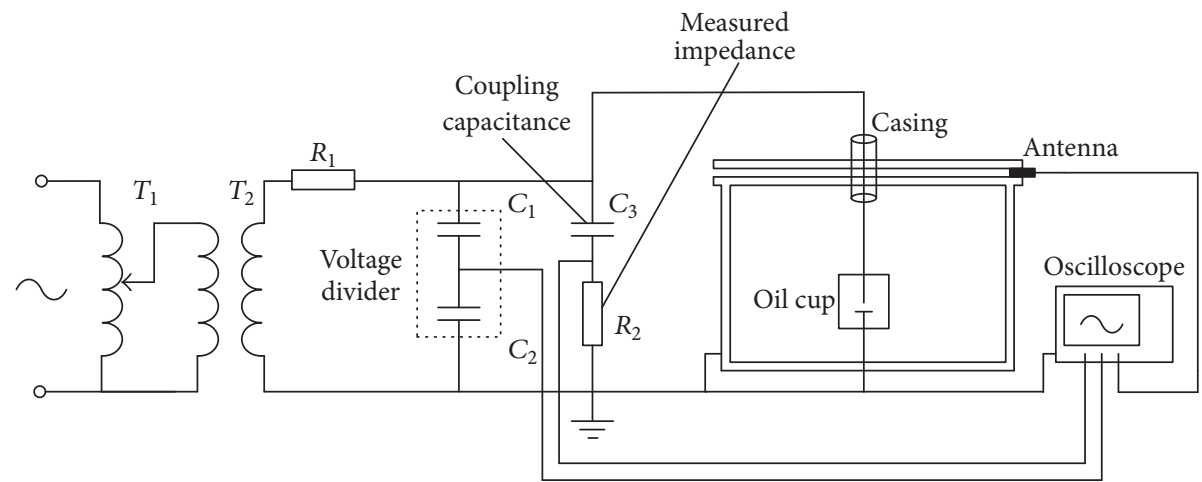

FIgURE 14: Experimental circuit diagram. 


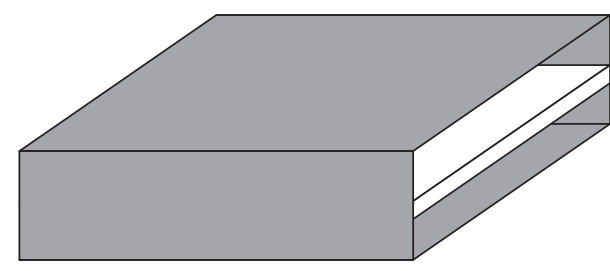

(a)

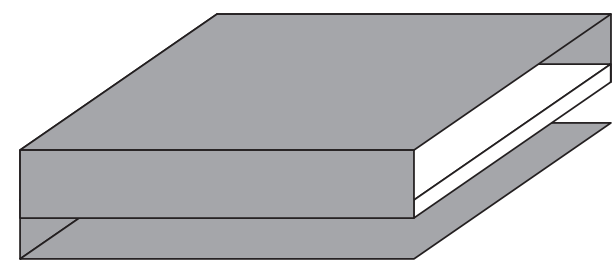

(b)

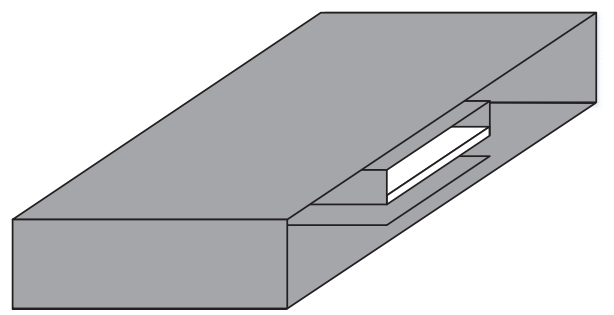

(c)

FIGURE 15: Antennas with three different metallic shells: (a) the front side of the metal box is removed; (b) the front side and a part of the flank of the metal box are removed; (c) two-layer metal box.

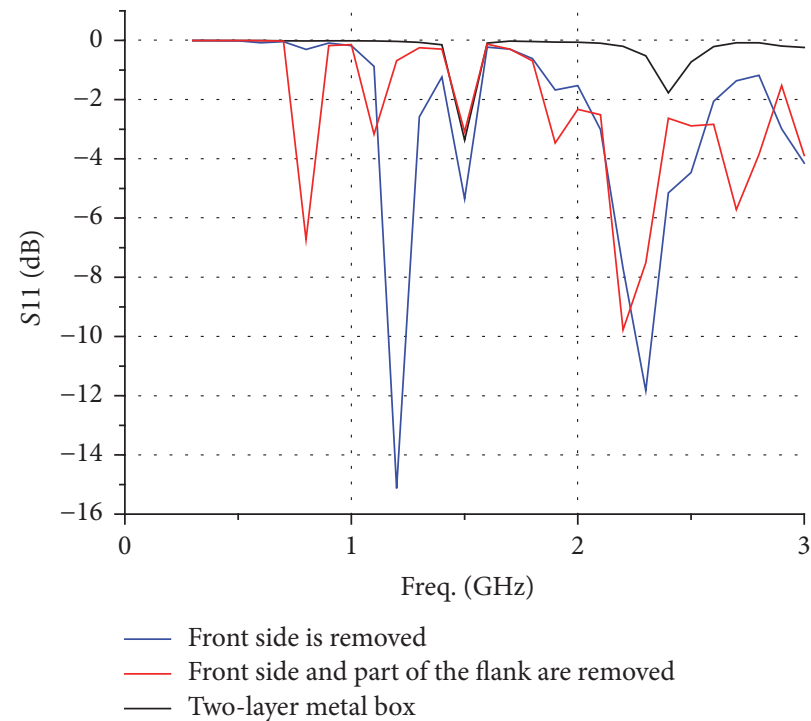

FIGURE 16: Return loss curves of antennas with three different metallic shells.

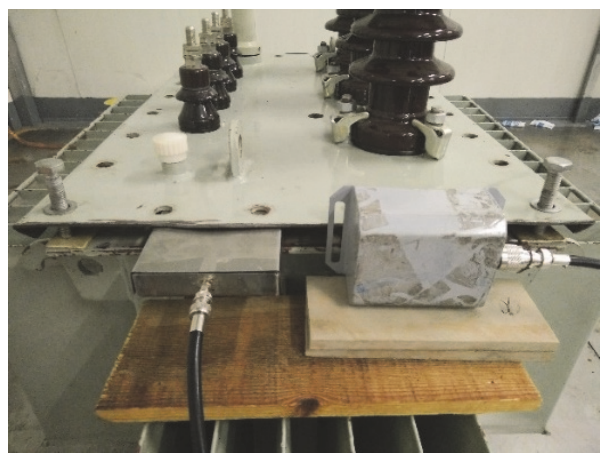

FIGURE 17: Placement of the antipodal Vivaldi antenna and rectangular plane spiral antenna. 

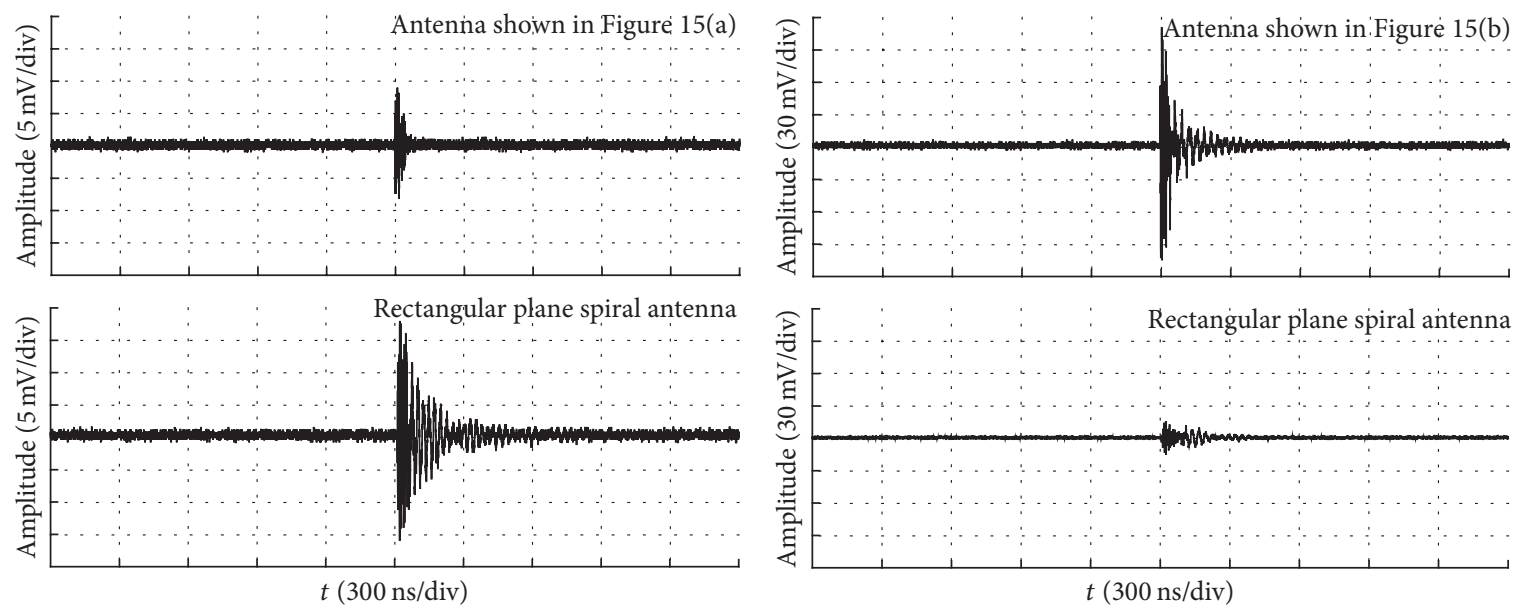

(a) Waveform of the signal received with the antenna shown in Figure 15(a) and the rectangular plane spiral antenna

(b) Waveform of the signal received with the antenna shown in Figure 15(b) and the rectangular plane spiral antenna
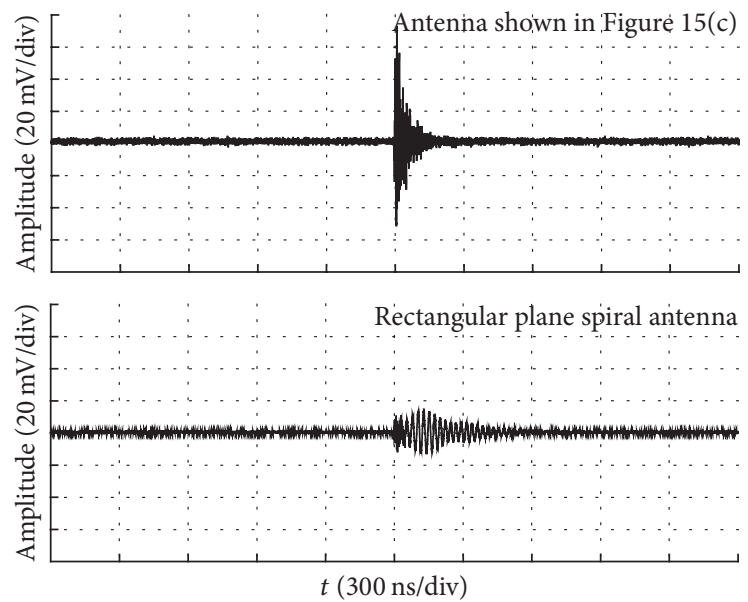

(c) Waveform of the signal received with the antenna shown in Figure 15(c) and the rectangular plane spiral antenna

FIGURE 18: Waveform of the signal received by antennas with three different metal boxes and the rectangular plane spiral antenna.

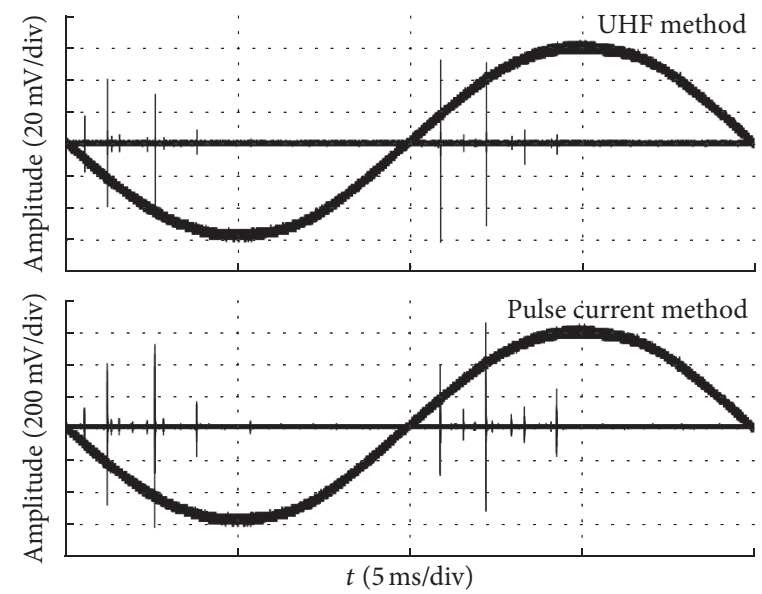

Figure 19: Partial discharge signals in a power-frequency cycle. 
and times of partial discharge are random, and whether the voltage of two electrodes is positive or negative exerts a minimal effect on them. Owing to the oscillation, every signal has both positive and negative components.

Comparison of the UHF and pulse current signals shows that the antipodal Vivaldi antenna exhibits excellent performance in terms of sensitivity. A large proportion of pulse current signals have their corresponding UHF signals, but their amplitude is uncorrelated.

\section{Conclusions}

Through simulation calculation and laboratory experiments, several conclusions were obtained:

(1) A linear gradient microstrip can effectively improve the performance of the antipodal Vivaldi antenna.

(2) The slot edge structure can significantly increase the gain of the antenna and improve the return loss to some extent.

(3) The metal around the antenna sharply reduces the return loss. By removing part of the flank of the metal box, the return loss is improved while maintaining the directivity of the antenna.

(4) The two-layer metal box can effectively shield against electromagnetic interference. Although the return loss is slightly deteriorated, the sensitivity of this antipodal Vivaldi antenna is much better than that of the rectangular plane spiral antenna. It can meet the demand of large transformer partial discharge monitoring.

(5) Needle-to-plate partial discharge in transformer oil mainly occurs in the one-fourth and three-fourth cycles. Whether the voltage of two electrodes is positive or negative exerts minimal effect on the amplitude and times of partial discharge.

\section{Conflicts of Interest}

The authors declare that they have no conflicts of interest regarding the publication of this paper.

\section{References}

[1] T. Babnik, R. K. Aggarwal, and P. J. Moore, "Principal component and hierarchical cluster analyses as applied to transformer partial discharge data with particular reference to transformer condition monitoring," IEEE Transactions on Power Delivery, vol. 23, no. 4, pp. 2008-2016, 2008.

[2] L.-J. Chen, T.-P. Tsao, and Y.-H. Lin, "New diagnosis approach to epoxy resin transformer partial discharge using acoustic technology," IEEE Transactions on Power Delivery, vol. 20, no. 4, pp. 2501-2508, 2005.

[3] M. Judd D, L. Yang, C. Bennoch J et al., "UHF diagnostic monitoring techniques for power transformers," in EPRI Substation Equipment Diagnostics Conference XII, 2004.

[4] M. D. Judd, O. Farish, J. S. Pearson, T. Breckenridge, and B. M. Pryor, "Power transformer monitoring using UHF sensors: installation and testing," in Proceedings of the ISEI 2000 - IEEE
International Symposium on Electrical Insulation, pp. 373-376, April 2000.

[5] W. Rutgers R and H. Fu Y, "UHF PD-Detection in a power transformer," in Proceedings of the 10th International Symposium on High Voltage Engineering, pp. 219-222, 1997.

[6] S. Zheng, C. Li, Z. Tang, W. Chang, and M. He, "Location of PDs inside transformer windings using UHF methods," IEEE Transactions on Dielectrics and Electrical Insulation, vol. 21, no. 1, pp. 386-393, 2014.

[7] R. Albarracín, J. A. Ardila-Rey, and A. A. Mas'Ud, "On the use of monopole antennas for determining the effect of the enclosure of a power transformer tank in partial discharges electromagnetic propagation," Sensors, vol. 16, no. 2, article 148, 2016.

[8] J. Li, T. Jiang, C. Wang, and C. Cheng, "Optimization of UHF Hilbert antenna for partial discharge detection of transformers," IEEE Transactions on Antennas and Propagation, vol. 60, no. 5, pp. 2536-2540, 2012.

[9] Z. Chaojie, Y. Yi, L. Yuncai, and F. Yijun, "One novel type of UHF antenna for locating partial discharge and simulation of UHF signal propagation within transformer," in Proceedings of the 2012 IEEE International Conference on Condition Monitoring and Diagnosis, CMD 2012, pp. 1179-1182, idn, September 2012.

[10] G. Wang, Y. Hao, and Y. Li, "Study on the ultra-high-frequency sensors for PD detection in power transformer," in Proceedings of 2001 International Symposium on. IEEE. Electrical Insulating Materials, pp. 793-796, 2001.

[11] J. Liu, G. Zhang, J. Dong, and J. Wang, "Study on miniaturized UHF antennas for partial discharge detection in high-voltage electrical equipment," Sensors, vol. 15, no. 11, pp. 29434-29451, 2015.

[12] A. J. Reid and M. D. Judd, "Identification of simultaneously active PD sources using passive comparison of UHF signals," in Proceedings of the Universities Power Engineering Conference, pp. 1-4, 2009.

[13] M. D. Judd, L. Yang, and I. B. B. Hunter, "Partial discharge monitoring for power transformers using UHF sensors part 1: Sensors and signal interpretation," IEEE Electrical Insulation Magazine, vol. 21, no. 2, pp. 5-14, 2005.

[14] J. Li, W. Si, and J. Yang, "Propagation characteristic of partial discharge ultra high frequency signals outside transformer," Journal of Xian Jiaotong University, vol. 42, no. 6, pp. 718-722, 2008 (Chinese).

[15] B. Xu, J. Wang, and Y.-M. Li, "Emulational study on the propagation of UHF signal emitted by PD in transformers," High Voltage Apparatus, vol. 43, no. 4, pp. 244-247, 2007.

[16] S. Wang, H. X. Zhao, and M. X. Fang, "UHF signal external detection of partial discharge in transformers," High Voltage Engineering, vol. 33, no. 8, pp. 88-91, 2007.

[17] S. Wang, L. X. Li, and H. J. Li, "Experimental study for outside propagation characteristic of the UHF signal emitted by partial discharge in transformers," High Voltage Apparatus, vol. 43, no. 2, pp. 100-105, 2007.

[18] J.-H. Li, W.-R. Si, P. Yuan, Y.-M. Li, and Y.-M. Li, "Propagation characteristic study of partial discharge UHF signal outside transformer," in Proceedings of the 2008 International Conference on Condition Monitoring and Diagnosis, pp. 1078-1080, 2008.

[19] S. S. Zheng, Location of Partial Discharges in Transformer Windings by Using UHF Method, North China Electric Power University, Beijing, China, 2015. 
[20] J. Shin and D. H. Schaubert, "A parameter study of stripline-fed Vivaldi notch-antenna arrays," IEEE Transactions on Antennas and Propagation, vol. 47, no. 5, pp. 879-886, 1999.

[21] E. Gazit, "Improved design of the Vivaldi antenna," IEE Proceedings H: Microwaves, Antennas and Propagation. IET Digital Library, vol. 135, no. 2, pp. 89-92, 1988.

[22] J. D. S. Langley, P. S. Hall, and P. N. Newham, "Novel ultrawidebandwidth Vivaldi antenna with low crosspolarisation," Electronics Letters, vol. 29, no. 23, pp. 2004-2005, 1993.

[23] M. C. Greenberg, K. L. Virga, and C. L. Hammond, "Performance characteristics of the dual exponentially tapered slot antenna (DETSA) for wireless communications applications," IEEE Transactions on Vehicular Technology, vol. 52, no. 2, pp. 305-312, 2003.

[24] H. Oraizi and S. Jam, "Optimum design of tapered slot antenna profile," IEEE Transactions on Antennas and Propagation, vol. 51, no. 8, pp. 1987-1995, 2003.

[25] P. Fei, Y.-C. Jiao, W. Hu, and F.-S. Zhang, "A miniaturized antipodal Vivaldi antenna with improved radiation characteristics," IEEE Antennas and Wireless Propagation Letters, vol. 10, pp. 127130, 2011.

[26] J. Bai, S. Shi, and D. W. Prather, "Modified compact antipodal Vivaldi antenna for 4-50-GHz UWB application," IEEE Transactions on Microwave Theory and Techniques, vol. 59, no. 4, pp. 1051-1057, 2011.

[27] S. Nikolaou, L. Marcaccioli, G. E. Ponchak, J. Papapolymerou, and M. M. Tentzeris, "Conformal Double Exponentially Tapered Slot Antennas (DETSA) for UWB communications systems' front-ends," in Proceedings of the ICU 2005: 2005 IEEE International Conference on Ultra-Wideband, pp. 196-200, September 2005.

[28] I. T. Nassar and T. M. Weller, "A novel method for improving antipodal Vivaldi antenna performance," IEEE Transactions on Antennas and Propagation, vol. 63, no. 7, pp. 3321-3324, 2015.

[29] M. Moosazadeh and S. Kharkovsky, "A compact high-gain and front-to-back ratio elliptically tapered antipodal vivaldi antenna with trapezoid-shaped dielectric lens," IEEE Antennas and Wireless Propagation Letters, vol. 15, pp. 552-555, 2016.

[30] H. Nakano, K. Kikkawa, Y. Iitsuka, and J. Yamauchi, "Equiangular spiral antenna backed by a shallow cavity with absorbing strips," IEEE Transactions on Antennas and Propagation, vol. 56, no. 8, pp. 2742-2747, 2008.

[31] W. Li, N. Shu, M. Lei et al., "Study on a rectangular plane spiral antenna for partial discharge detection in GIS," High Voltage Engineering, vol. 40, no. 11, pp. 3418-3423, 2014 (Chinese). 


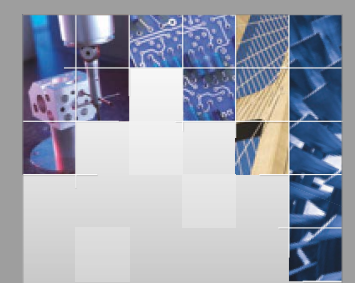

\section{Enfincering}
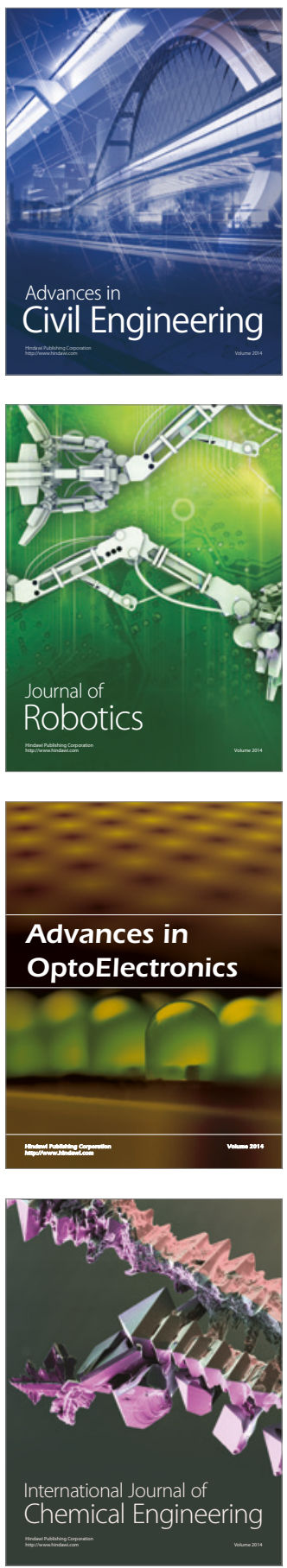

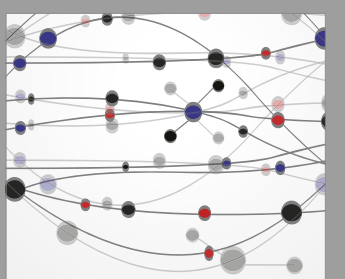

The Scientific World Journal

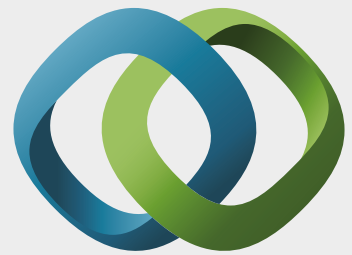

\section{Hindawi}

Submit your manuscripts at

https://www.hindawi.com
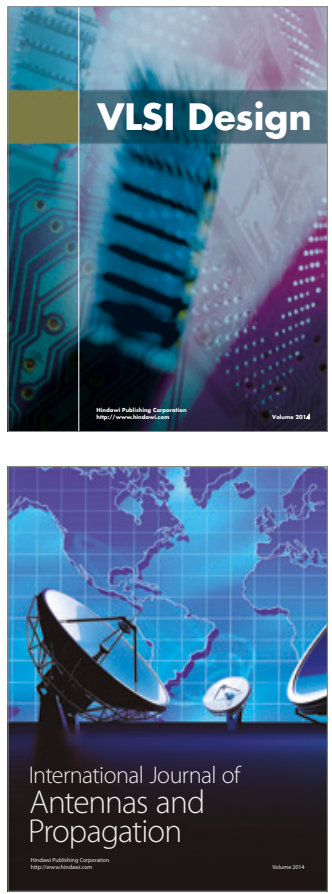

\section{Rotating}

Machinery
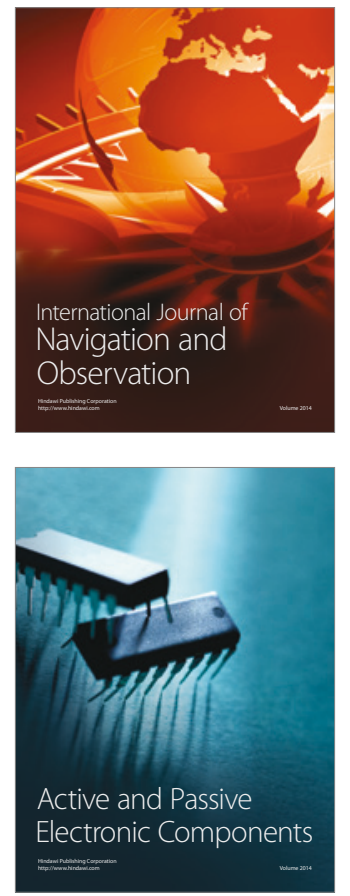
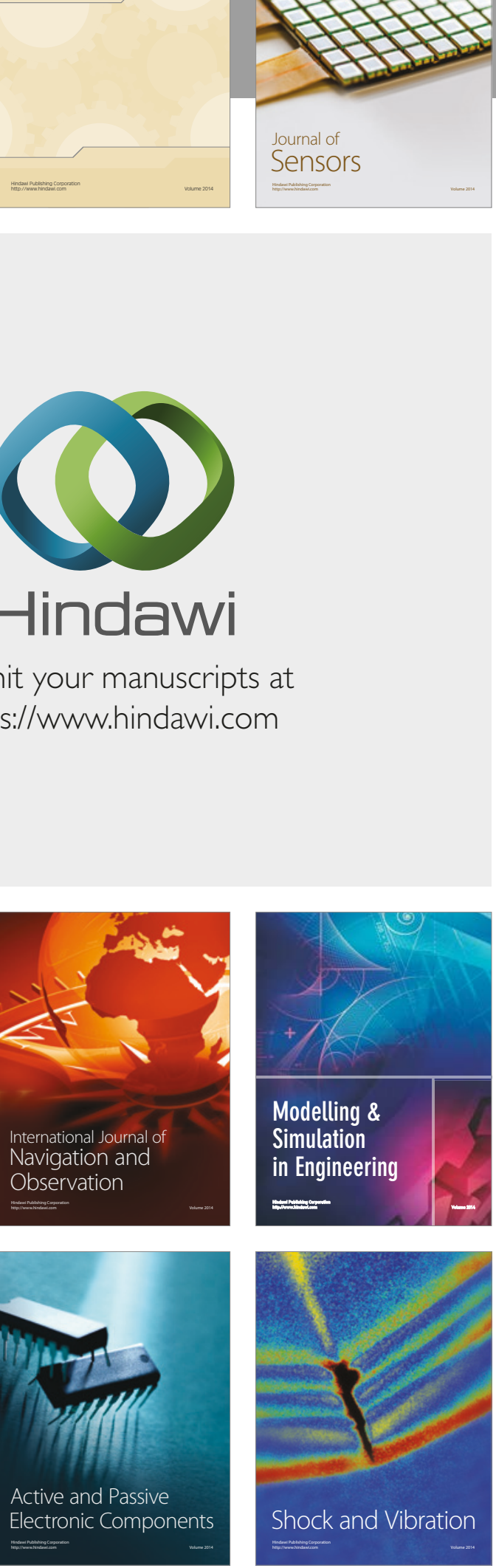
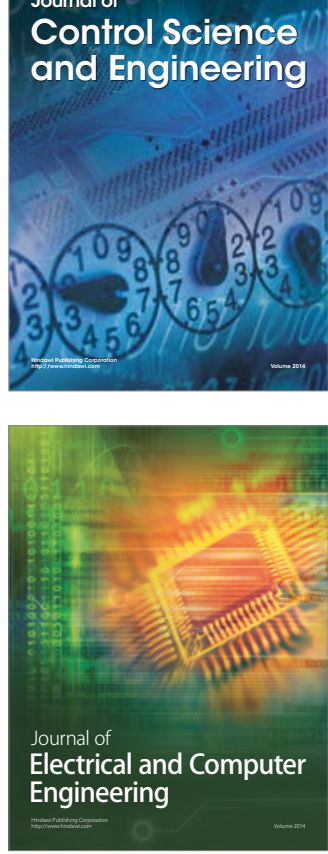

Distributed

Journal of

Control Science

and Engineering
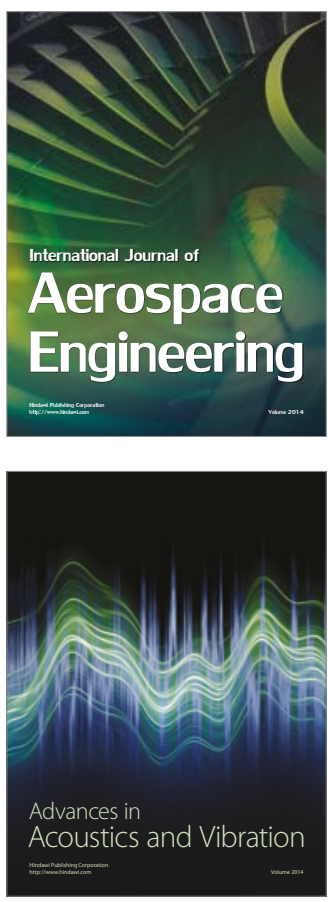

Sensor Networks 